\title{
antibiotics
}

ISSN 2079-6382

www.mdpi.com/journal/antibiotics

Review

\section{The Role of Antifungals against Candida Biofilm in Catheter-Related Candidemia}

\author{
Emilio Bouza ${ }^{1,2,3}$, Jesús Guinea ${ }^{1,2}$ and María Guembe ${ }^{1, *}$ \\ 1 Department of Clinical Microbiology and Infectious Diseases, Gregorio Marañón Hospital, \\ Madrid 28007, Spain; E-Mails: ebouza@microb.net (E.B.); jguineaortega@yahoo.es (J.G.) \\ 2 Medicine Department, School of Medicine, Universidad Complutense de Madrid, Madrid 28040, Spain \\ 3 CIBER de Enfermedades Respiratorias (CIBER RES), CB06/06/0058, Madrid, Spain \\ * Author to whom correspondence should be addressed; E-Mail: mariaguembe@hotmail.com; \\ Tel.: +34-915-868-027; Fax: +34-915-044-906.
}

Academic Editor: Dr. Christopher C. Butler

Received: 11 October 2014 / Accepted: 9 December 2014 / Published: 25 December 2014

\begin{abstract}
Catheter-related bloodstream infection (C-RBSI) is one of the most frequent nosocomial infections. It is associated with high rates of morbidity and mortality. Candida spp. is the third most common cause of C-RBSI after coagulase-negative staphylococci and Staphylococcus aureus and is responsible for approximately $8 \%$ of episodes. The main cause of catheter-related candidemia is the ability of some Candida strains - mainly C. albicans and C. parapsilosis - to produce biofilms. Many in vitro and in vivo models have been designed to assess the activity of antifungal drugs against Candida biofilms. Echinocandins have proven to be the most active antifungal drugs. Potential options in situations where the catheter cannot be removed include the combination of systemic and lock antifungal therapy. However, well-designed and -executed clinical trials must be performed before firm recommendations can be issued.
\end{abstract}

Keywords: biofilm; Candida; antifungals; catheter-related candidemia

\section{Introduction}

Candida spp. is the third leading cause of catheter-related infections after coagulase-negative staphylococci and Staphylococcus aureus. It is associated with high rates of crude mortality [1-3]. 
C. albicans and C. parapsilosis are the most frequent fungi in hospitalized patients and in hospital environments [4]. They are also the species that most commonly produce biofilm, a characteristic that facilitates persistent infections, such as catheter-related candidemia (CRC) [5-10]. Non-Candida biofilms have also been studied, and the lowest metabolic activity was recently reported by Marcos-Zambrano et al. [11]. Recent findings also support the hypothesis that surface-associated filamentous fungi can form biofilms [12].

Most studies based on the role of biofilm in infections have been performed with bacteria. Data on the peculiarities of Candida biofilm and its clinical significance are scarce and come mainly from studies on the ability of antifungals to eradicate biofilm.

We performed an exhaustive review of Candida biofilm and its eradication with antifungals in CRC.

\section{Catheter-Related Candidemia}

Many episodes of candidemia originate in central venous catheters (CVCs) $[5,13]$, leading to high rates of morbidity and mortality [14]. The ability of some Candida strains to produce biofilms - mainly C. albicans and C. parapsilosis - may explain the high frequency of CRC.

Diagnosis of CRC is problematic, owing to the lack of appropriate microbiologic procedures and the difficulty in eradicating Candida biofilms [15-17].

\section{Candida Biofilm}

\subsection{Composition}

Some bacteria and fungi have the ability to form cell aggregates. In combination with other host components (e.g., fibrin, platelets and immunoglobulins), these aggregates comprise the complex structure of biofilm, which is surrounded by a polymer matrix. Biofilm-producing bacteria or fungi can adhere to natural or artificial surfaces, where the properties they express differ from the properties of their planktonic forms. Consequently, they are more virulent and can cause chronic infections $[6,18,19]$.

\subsection{Formation}

Fungal biofilms are increasingly common as a result of the widespread use of antibiotics, medical devices and the increase in the number of immunocompromised patients [8,20,21]. Candida biofilm results from an initial attachment of cells to glycoprotein-coated host cells and tissue or biomaterial surfaces. The second phase (proliferation and biofilm formation) is characterized by the generation of a three-dimensional structure [22-24], which is highly dependent on the conditions under which the biofilm is formed (e.g., type of implanted device and its location) [7,18,25].

\subsection{Genetic Mechanisms of Biofilm Formation}

Several molecular factors are associated with biofilm formation. Quorum sensing could play an important role in the dispersal of biofilm cells and the formation of amyloid-dependent adhesion nanodomains and has broad implications as a mechanism underlying yeast cell-cell adhesion and biofilms [26-28]. Differential gene expression was recently demonstrated in Candida cells under 
planktonic conditions or as biofilm. The major functional categories of genes upregulated in biofilms are those implicated in transcriptional regulation, protein synthesis, amino acid synthesis, cell wall synthesis, efflux pumps and adhesins [29-31].

\subsection{Measurement of Biofilm Formation}

Fungal biofilm formation and eradication of biofilm by antifungals can be assessed using in vitro approaches (microtiter plate-based models, flow displacement biofilm models, cell-culture-based models and microfluidic device models) and in vivo approaches (CVC models, subcutaneous and intraperitoneal foreign body infection models, urinary tract infection models, ear-nose-throat infection models, respiratory tract infection models and osteomyelitis infection models) [32-38]. The most common colorimetric assays for measuring biofilm formation and metabolic activity are, respectively, the crystal binding violet assay and the XTT assay (based on 2,3-bis[2-methoxy-4-nitro-5sulfophenyl]2H-tetrazolium-5-carboxanilide inner salt) [39-46]. However, there are still no standard cut-offs to establish whether a Candida strain has high, moderate or low capacity to produce biofilm. Growth of biofilm can also be visualized in situ by means of scanning electron microscopy, which is the most commonly used method [33].

\subsection{Clinical Aspects of Candida Biofilm}

The incidence of biofilm-producing Candida strains recovered from the blood of candidemic patients was reported to be $83.3 \%$ in both the general population and immunocompromised patients $[47,48]$. Ruiz et al. reported a 100\% incidence rate of biofilm-producing C. parapsilosis strains recovered from children's blood [49]. These findings have a major clinical impact, because of the increase in antifungal resistance and protection against host defenses. Moreover, fungal biofilm on medical devices, such as CVCs, could act as a reservoir for re-infection and necessitate catheter withdrawal [50-52]. Another important factor associated with Candida biofilm formation is the administration of lipid emulsion to patients via CVCs, which has been shown to induce germination and enhance biofilm production [53]. Catheter-related bloodstream infections (C-RBSIs) occur in $1.3 \%$ to $26.2 \%$ of patients with CVCs used to administer parenteral nutrition [54]. However, the role of biofilm production in clinical outcome is still being explored.

\section{Antifungal Activity against Candida Biofilm}

\subsection{In Vitro Activity of Antifungals to Eradicate Candida Biofilm}

The efficacy of antifungals against Candida biofilms has been tested in numerous in vitro studies. Amphotericin B (AmB) and echinocandins proved to be the most active agents against Candida biofilms. Azoles had little effect against Candida biofilms, even at high doses and in combination with caspofungin [55-58]. However, fluconazole combined with minocycline had a synergistic effect against fluconazole-resistant $C$. albicans, probably owing to the boosting of fluconazole by minocycline as it penetrates biofilm [59].

Most studies evaluating AmB compared it with other families of antifungals. AmB generally has a good anti-biofilm effect at high doses of the liposomal form (AmB-L) [56,60,61]. This observation was 
also validated by Uppuluri et al., who examined the effect of continuous perfusion with AmB on C. albicans biofilms under conditions of flow [57]. Moreover, Tobudic et al. evaluated the anti-biofilm effect of AmB in combination with caspofungin and posaconazole against $C$. albicans planktonic and sessile cells and demonstrated that the combination of $\mathrm{AmB} /$ posaconazole was synergistic against C. albicans biofilms, whereas $\mathrm{AmB} /$ caspofungin produced an indifferent interaction [62]. Poorer results were seen when AmB was tested against biofilms of C. parapsilosis [55].

Studies evaluating the susceptibility of Candida biofilms to echinocandins showed that, although planktonic cells of Candida spp. were susceptible to all three echinocandins, the MICs of sessile cells were higher [63,64]. Even so, caspofungin and micafungin were active against $C$. albicans and $C$. glabrata biofilms, but not against $C$. tropicalis and $C$. parapsilosis biofilms $[65,66]$. Anidulafungin has also been tested alone and in combination with other antifungals and proved highly active against both planktonic and sessile cells, with planktonic and sessile MICs for $50 \%$ and $90 \%$ of the isolates tested ( MIC $_{50}$ and $\mathrm{MIC}_{90}$ ) of $\leq 0.03 \mu \mathrm{g} / \mathrm{mL}$ to $<0.125 \mu \mathrm{g} / \mathrm{mL}$ and $\leq 0.03 \mu \mathrm{g} / \mathrm{mL}$ to $\leq 0.03 \mu \mathrm{g} / \mathrm{mL}$, respectively [67,68]. When anidulafungin was compared with $\mathrm{AmB}$, it displayed more activity than AmB against $C$. albicans biofilms after 24 h of maturation; however, AmB was more active against more mature biofilms ( $>48 \mathrm{~h}$ ) [69]. Compared with azoles, anidulafungin had the lowest sessile MIC 90 $(0.063-0.125 \mu \mathrm{g} / \mathrm{mL} v s . \geq 64 \mu \mathrm{g} / \mathrm{mL})$, which was also maintained in long-term trials of continuous flow culture [70-72].

Similar results have been found in studies assessing the activity of micafungin against planktonic and sessile cells of Candida strains isolated from clinical samples: sessile MICs were higher than planktonic MICs in both C. albicans and C. parapsilosis [64,73].

However, in the case of antifungal lock therapy (ALT), high-dose echinocandins, especially caspofungin, had paradoxical effects on Candida biofilms [63,74-76]. Anidulafungin had the weakest in vitro paradoxical effect [77]. The clinical relevance of paradoxical effects remains unknown, although more and more data suggest that they might be overrated.

As for the inhibition of the metabolism of sessile cells, Cocuaud et al. found that caspofungin used at $2 \mu \mathrm{g} / \mathrm{mL}$ significantly decreased the metabolism of all of the strains of C. albicans and C. parapsilosis tested, independently of biofilm maturation [78]. A recent study by our group also demonstrated that concentrations of micafungin above $2 \mu \mathrm{g} / \mathrm{mL}$ were sufficient to inactivate re-growth of sessile Candida cells [64], as suggested in a previous study by Kaneko et al., who analyzed real-time data comprising time-lapse images taken at brief intervals. Their results showed that, unlike fluconazole, micafungin contributed not only to fungicidal activity, but also to the immediate suppression of biofilm growth [79]. However, in an in vitro model of Candida biofilms on polystyrene and CVC sections, Seidler et al. found that micafungin could not reduce metabolic activity completely, even at the highest concentration [80].

Other in vitro studies have been carried out to increase the anti-biofilm effect of antifungals by administering them at high concentrations (ALT) in combination with systemic treatment. Toulet et al. found that AmB-L lock solutions $(1000 \mu \mathrm{g} / \mathrm{mL})$ strongly inhibited Candida spp. in young and mature biofilms for up to $48 \mathrm{~h}$ after the end of the lock period [81]. In their study of AmB and caspofungin, Oncü et al. reported similar findings, with a significant decrease in the C. albicans and C. parapsilosis colony count from baseline until the fifth day, when the catheters were completely sterile [82]. Other studies testing high doses of caspofungin and micafungin in silicone catheters also found reductions in the yeast metabolic activity of intermediate and mature biofilms (between $12 \mathrm{~h}$ and five days) $[83,84]$. 
In contrast, Ko et al. tested the in vitro activity of ALT against C. albicans, C. glabrata and C. tropicalis biofilms using five antifungal agents in polyurethane catheters and showed that only azoles were able to eliminate the viability of the biofilms of all Candida species within 7, 10 and 14 days [85].

New approaches are being developed to improve the effect of ALT by combining it with other non-antibiotic/antifungal agents. The addition of chelators, especially in combinations, is an innovative and superior alternative to heparin lock solution in the prevention and treatment of CRC. Cinnamon oil was effective against $C$. parapsilosis biofilms at $250 \mu \mathrm{g} / \mathrm{mL}$, although it did not show a synergistic effect when combined with AmB [86]. Xanthorrhizol at $128 \mu \mathrm{g} / \mathrm{mL}$ exhibited potent activity against C. glabrata, C. guilliermondii and C. parapsilosis biofilms at the mature growth phase [87]. Percival et al. showed that using $40 \mathrm{mg} / \mathrm{mL}$ of tetrasodium EDTA in a lock solution for at least $21 \mathrm{~h}$ significantly reduced CVC-associated biofilms in a C. albicans model [88]. Rane et al. demonstrated that concentrations of 35\% ethanol or higher for a minimum of $4 \mathrm{~h}$ reduced the metabolic activity of mature $C$. albicans biofilm by more than $>99 \%$ and prevented re-growth [89]. Minocycline-EDTA-25\% ethanol fully eradicated Gram-positive, Gram-negative and fungal biofilms within $2 \mathrm{~h}$ and completely prevented re-growth [90,91]. Moreover, a solution combining $0.01 \%$ glyceryl trinitrate with $7 \%$ citrate and $20 \%$ ethanol showed a synergistic effect in eradicating C. albicans biofilms in an in vitro model of catheter colonization [92].

\subsection{In Vivo Activity of Antifungals Administered to Eradicate Candida Biofilms}

Recent in vivo studies analyzed the efficacy of antifungals against Candida biofilms in both systemic and lock therapy. AmB-L was able to eradicate C. albicans biofilms formed on catheters placed in rabbits exposed to AmB-L lock therapy $[93,94]$. In contrast, when deoxycholate AmB (AmB-D) was compared to caspofungin in a model combining systemic and intraluminal lock therapy for seven days, caspofungin was more effective at eradicating C. albicans biofilms [95]. Moreover, caspofungin showed promising results when tested in lock therapy to prevent $C$. albicans biofilms in a murine model [96]. Kucharikova et al. found that all echinocandins were effective against $C$. albicans biofilms developed in a subcutaneous catheter rat model when administered intravenously for 5, 7 and 10 days [97]. Testing of anidulafungin against mature $C$. albicans biofilms in rats showed that seven-day systemic administration reduced cell numbers in catheters retrieved from treated animals compared with those retrieved from untreated and fluconazole-treated animals [98].

\subsection{Clinical Studies on the Management of Candida Biofilm in CRC}

\subsubsection{Therapeutic Approaches}

International clinical practice guidelines for the management of candidiasis recommend withdrawing the catheter when there is suspicion of CRC [99]. However, this approach is problematic in the case of indwelling catheters, such as tunneled catheters or totally implantable venous access ports. Replacement of these catheters requires surgery and is expensive. Moreover, patients with these types of catheters (patients receiving parenteral nutrition, hemodialysis or chemotherapy) may not have any other available vascular access [100]. Therefore, some authors are considering the possibility of managing patients with CRC while the catheter remains in place [101-103]. Garnacho-Montero et al. evaluated the outcome of candidemic patients with CVC and found that delay in catheter withdrawal and in administration of 
adequate antifungal therapy was associated with increased mortality [104]. In contrast, Nucci et al. found that early removal of CVCs in non-neutropenic patients was of no clinical benefit when patients were covered with antifungals that were active against biofilm [101]. This finding was supported by other authors, who showed that outcome was better in patients with candidemia receiving highly active anti-biofilm agents [105]. It seems that that timing of CVC removal is best determined after carefully considering risks and benefits and that adequate anti-biofilm antifungal therapy is the key to better outcome $[2,106]$.

Biofilm is not associated with increased mortality or development of CRC. Tortorano et al. found that $25.7 \%$ of Candida isolates from blood presented high biofilm-forming ability, but they did not find differences in the crude mortality rate according to this ability in C. albicans and non-albicans Candida $(33.3 \%$ vs. $24.1 \%$, OR = 1.57) [13]. A similar study performed recently by our group revealed no differences in mortality rate between patients colonized by biofilm-forming isolates and patients colonized by non-biofilm-forming isolates $(24.4 \%$ vs. $22.2 \%, p=0.776)$ and that biofilm production was not a good predictor of CRC [48].

The approaches developed in recent years to address management of CRC include catheter lock antiseptic solutions, antiseptic-coated catheters and Luer-activated needleless connectors have been optimized in recent years $[88,89,91,92,107-113]$.

ALT is a novel therapeutic approach in catheter salvage that has been described in in vitro and in vivo studies. The procedure consists of filling the catheter lumen with high doses of antibiotic/antifungal solution alone or in combination with other components for a period of time during which systemic toxicity is avoided and serum drug levels are monitored. The recommended period for treating an episode of C-RBSI with combined systemic treatment, and ALT is 7-14 days after the last negative blood culture (instillation periods of between $2 \mathrm{~h}$ and $48 \mathrm{~h}$ ) [114]. The success rate of ALT in catheter salvage described in C-RBSI and CRC is between $71.4 \%$ and $82 \%[115,116]$. Most studies describing the outcome of patients receiving systemic treatment and ALT were performed with AmB-D and AmB-L, which were associated with a $60 \%$ salvage rate [117-127]. Blackwood et al. performed the only study with azoles. Three patients were successfully treated with systemic fluconazole or voriconazole in combination with ethanol lock therapy [128]. As for echinocandins, the literature contains only one report of a patient treated with systemic caspofungin in combination with ALT: the patient had C. lipolytica CRC that was treated successfully without removing the catheter [120]. Recently, five of seven cases of CRC (71.4\%) were successfully treated with ethanol lock therapy and systemic echinocandins [115].

In extra-luminal biofilm, cells do not detach as easily from the biofilm; however, some clinical failures of ALT could be due to the presence of extra-luminal biofilm.

Even though most research articles based on clinical studies point out that micafungin is one the most active agents with anti-biofilm effects in adult and pediatric populations [129-133], future research is needed to evaluate its anti-biofilm effect in the management of CRC by combining systemic treatment and lock therapy.

\subsubsection{Novel Preventive Approaches}

In order to improve the management of CRC caused by biofilm-forming Candida, preventive measures, such as antiseptic-coated catheters and Luer-activated needleless connectors, have been optimized in recent years. 
Privet et al. demonstrated that the combination of nitric-oxide with silver sulfadiazine had a synergistic effect against adhesion and biofilm formation in C. albicans [134]. Roe et al. showed that plastic catheters coated with bioactive silver nanoparticles had significant in vitro antimicrobial activity and provided 10 days' protection against the formation of C. albicans biofilm [135]. Other authors found that the formation of Candida biofilm could be prevented with chlorhexidine-minocycline-rifampin-impregnated catheters alone and in combination with gendine [110,136]. These impregnated catheters have proven effective both in vitro and in vivo. Cobrado et al. showed that subinhibitory concentrations of cerium nitrate and chitosan significantly reduced biofilm formation by $C$. albicans, making both options promising alternatives for coating CVCs [109]. Martínez et al. also showed chitosan to be active against fungal biofilms at doses that were not toxic for human endothelial cells [113].

Impregnated catheters had been tested in clinical studies of adult critical care patients. Khare et al. demonstrated diminished catheter colonization using a silver zeolite-impregnated CVC [112], and Carrasco et al. showed that the use of CVCs coated with chlorhexidine and silver sulfadiazine reduced the risk of catheter colonization by Candida spp. [137]. Walz et al. showed that CVCs coated with 5-fluorouracil were also effective against colonization and could serve as an alternative to catheters externally coated with chlorhexidine and silver sulfadiazine [138].

Other novel preventive strategies, such us antiseptic barrier caps for needleless connectors, have proven effective in the prevention of contamination, both in vitro and in clinical studies [111,139-141].

Table 1. Summary.

\section{Candida Biofilm}

- Candida biofilm is produced by an initial attachment of cells coated with glycoproteins that progresses to a three-dimensional structure.

- C. albicans and C. parapsilosis are two of the main biofilm-producing species.

- The ability of these strains to produce biofilms may explain the high frequency of CRC.

- Fungal biofilm on CVCs could act as a reservoir for re-infection and necessitate catheter withdrawal.

\section{Activity of antifungals against Candida biofilm}

- Echinocandins are the most active agents against Candida biofilms in in vitro and in vivo models.

- The MIC profiles of echinocandins in sessile cells are higher than in planktonic cells.

- AmB-L had a good anti-biofilm effect when used at high doses.

- In general, in vitro studies demonstrated that the anti-biofilm effect of antifungals increased when the drugs were used at high concentrations (ALT).

- The addition of chelators to ALT provides an innovative and superior alternative to heparin lock solution in the prevention and treatment of CRC.

\section{Clinical aspects of Candida biofilms}

- Adequate anti-biofilm antifungal therapy, rather than early CVC removal, is the key factor for a better outcome.

- The optimal period for treating an episode of CRC with a combination of systemic agents and ALT is 7-14 days after the last negative blood culture.

- The therapeutic success rate of ALT with catheter salvage in CRC is between $71.4 \%$ and $82 \%$.

- Most studies describing the outcome of patients receiving systemic treatment and ALT are performed with AmB-D and L-AmB, which were associated with a $60 \%$ catheter salvage rate.

- In recent years, preventive measures, such as antiseptic coated catheters and Luer-activated needleless connectors, have been optimized to improve the management of CRC.

CRC, catheter-related candidemia; CVC, central venous catheter; L-AmB, liposomal amphotericin B;

ALT, antifungal lock therapy; AmB-D, amphotericin B deoxycholate. 


\section{Conclusions}

Numerous in vitro and in vivo models of CRC have demonstrated the effectiveness of antifungals, especially echinocandins, both alone and in combination with other components in the eradication of Candida biofilms (Table 1). However, more prospective studies should be performed to evaluate the clinical significance of these findings by combining systemic antifungals with ALT in patients with CRC for whom catheter removal could pose more of a risk than a benefit.

\section{Acknowledgements}

We thank Thomas O'Boyle for his help in the preparation of the manuscript. M. Guembe (MS13/00268) and J. Guinea (MS09/00055) are supported by the Fondo de Investigación Sanitaria.

\section{Author Contributions}

Emilio Bouza and Jesús Guinea have monitored the review. María Guembe has written the review.

\section{Conflicts of Interest}

The authors declare no conflicts of interest.

\section{References}

1. Crump, J.A.; Collignon, P.J. Intravascular catheter-associated infections. Eur. J. Clin. Microbiol. Infect. Dis. 2000, 19, 1-8.

2. Weinberger, M.; Leibovici, L.; Perez, S.; Samra, Z.; Ostfeld, I.; Levi, I.; Bash, E.; Turner, D.; Goldschmied-Reouven, A.; Regev-Yochay, G.; et al. Characteristics of candidaemia with Candida-albicans compared with non-albicans Candida species and predictors of mortality. J. Hosp. Infect. 2005, 61, 146-154.

3. Velasco, E.; Bigni, R. A prospective cohort study evaluating the prognostic impact of clinical characteristics and comorbid conditions of hospitalized adult and pediatric cancer patients with candidemia. Eur. J. Clin. Microbiol. Infect. Dis. 2008, 27, 1071-1078.

4. Ferreira, A.V.; Prado, C.G.; Carvalho, R.R.; Dias, K.S.; Dias, A.L. Candida albicans and non-C. albicans Candida species: Comparison of biofilm production and metabolic activity in biofilms, and putative virulence properties of isolates from hospital environments and infections. Mycopathologia 2012, 175, 265-272.

5. Goldmann, D.A.; Pier, G.B. Pathogenesis of infections related to intravascular catheterization. Clin. Microbiol. Rev. 1993, 6, 176-192.

6. Donlan, R.M. Biofilm formation: A clinically relevant microbiological process. Clin. Infect. Dis. 2001, 33, 1387-1392.

7. Kumamoto, C.A. Candida biofilms. Curr. Opin. Microbiol. 2002, 5, 608-611.

8. Ramage, G.; Saville, S.P.; Thomas, D.P.; Lopez-Ribot, J.L. Candida biofilms: An update. Eukaryot. Cell 2005, 4, 633-638. 
9. Silva, S.; Negri, M.; Henriques, M.; Oliveira, R.; Williams, D.W.; Azeredo, J. Adherence and biofilm formation of non-Candida albicans Candida species. Trends Microbiol. 2011, 19, 241-247.

10. Silva, S.; Henriques, M.; Martins, A.; Oliveira, R.; Williams, D.; Azeredo, J. Biofilms of non-Candida albicans Candida species: Quantification, structure and matrix composition. Med. Mycol. 2009, 47, 681-689.

11. Marcos-Zambrano, L.J.; Escribano, P.; Bouza, E.; Guinea, J. Production of biofilm by Candida and non-Candida spp. isolates causing fungemia: Comparison of biomass production and metabolic activity and development of cut-off points. Int. J. Med. Microbiol. 2014, 304, 1192-1198.

12. Harding, M.W.; Marques, L.L.; Howard, R.J.; Olson, M.E. Can filamentous fungi form biofilms? Trends Microbiol. 2009, 17, 475-480.

13. Tortorano, A.M.; Prigitano, A.; Lazzarini, C.; Passera, M.; Deiana, M.L.; Cavinato, S.; de Luca, C.; Grancini, A.; Lo Cascio, G.; Ossi, C.; et al. A 1-year prospective survey of candidemia in Italy and changing epidemiology over one decade. Infection 2013, 41, 655-662.

14. Wey, S.B.; Mori, M.; Pfaller, M.A.; Woolson, R.F.; Wenzel, R.P. Hospital-acquired candidemia. The attributable mortality and excess length of stay. Arch. Intern. Med. 1988, 148, 642-645.

15. Ben-Ami, R.; Weinberger, M.; Orni-Wasserlauff, R.; Schwartz, D.; Itzhaki, A.; Lazarovitch, T.; Bash, E.; Aharoni, Y.; Moroz, I.; Giladi, M. Time to blood culture positivity as a marker for catheter-related candidemia. J. Clin. Microbiol. 2008, 46, 2222-2226.

16. Fernandez-Cruz, A.; Martin-Rabadan, P.; Suarez-Salas, M.; Rojas-Wettig, L.; Perez, M.J.; Guinea, J.; Guembe, M.; Peláez, T.; Sánchez-Carrillo, C.; Bouza, E. Is it feasible to diagnose catheter-related candidemia without catheter withdrawal? Med. Mycol. 2014, 52, 491-497.

17. Bouza, E.; Alcala, L.; Munoz, P.; Martin-Rabadan, P.; Guembe, M.; Rodriguez-Creixems, M. Can microbiologists help to assess catheter involvement in candidaemic patients before removal? Clin. Microbiol. Infect. 2013, 19, E129-E135.

18. Donlan, R.M.; Costerton, J.W. Biofilms: Survival mechanisms of clinically relevant microorganisms. Clin. Microbiol. Rev. 2002, 15, 167-193.

19. Donlan, R.M. Biofilms and device-associated infections. Emerg. Infect. Dis. 2001, 7, 277-281.

20. Ramage, G.; Williams, C. The clinical importance of fungal biofilms. Adv. Appl. Microbiol. 2013, $84,27-83$.

21. Ramage, G.; Mowat, E.; Jones, B.; Williams, C.; Lopez-Ribot, J. Our current understanding of fungal biofilms. Crit. Rev. Microbiol. 2009, 35, 340-355.

22. Ramage, G.; Vandewalle, K.; Wickes, B.L.; Lopez-Ribot, J.L. Characteristics of biofilm formation by Candida albicans. Rev. Iberoam. Micol. 2001, 18, 163-170.

23. Nett, J.; Andes, D. Candida albicans biofilm development, modeling a host-pathogen interaction. Curr. Opin. Microbiol. 2006, 9, 340-345.

24. Blankenship, J.R.; Mitchell, A.P. How to build a biofilm: A fungal perspective. Curr. Opin. Microbiol. 2006, 9, 588-594.

25. Baillie, G.S.; Douglas, L.J. Role of dimorphism in the development of Candida albicans biofilms. J. Med. Microbiol. 1999, 48, 671-679.

26. Hornby, J.M.; Jensen, E.C.; Lisec, A.D.; Tasto, J.J.; Jahnke, B.; Shoemaker, R.; Dussault, P.; Nickerson, K.W. Quorum sensing in the dimorphic fungus Candida albicans is mediated by farnesol. Appl. Environ. Microbiol. 2001, 67, 2982-2992. 
27. Garcia, M.C.; Lee, J.T.; Ramsook, C.B.; Alsteens, D.; Dufrene, Y.F.; Lipke, P.N. A role for amyloid in cell aggregation and biofilm formation. PLOS ONE 2011, 6, e17632.

28. Deveau, A.; Hogan, D.A. Linking quorum sensing regulation and biofilm formation by Candida albicans. Methods Mol. Biol. 2011, 692, 219-233.

29. Fanning, S.; Mitchell, A.P. Fungal biofilms. PLoS Pathog. 2012, 8, e1002585.

30. Chandra, J.; Kuhn, D.M.; Mukherjee, P.K.; Hoyer, L.L.; McCormick, T.; Ghannoum, M.A. Biofilm formation by the fungal pathogen Candida albicans: Development, architecture, and drug resistance. J. Bacteriol. 2001, 183, 5385-5394.

31. Nett, J.E.; Sanchez, H.; Cain, M.T.; Ross, K.M.; Andes, D.R. Interface of Candida albicans biofilm matrix-associated drug resistance and cell wall integrity regulation. Eukaryot Cell. 2011, 10, 1660-1669.

32. Coenye, T.; Nelis, H.J. In vitro and in vivo model systems to study microbial biofilm formation. J. Microbiol. Methods 2010, 83, 89-105.

33. Hawser, S.P.; Douglas, L.J. Biofilm formation by Candida species on the surface of catheter materials in vitro. Infect. Immun. 1994, 62, 915-921.

34. Uppuluri, P.; Lopez-Ribot, J.L. An easy and economical in vitro method for the formation of Candida albicans biofilms under continuous conditions of flow. Virulence 2010, 1, 483-487.

35. Lebeaux, D.K.I.; Decante, B.; Ghigo, J.; Beloin, C.; Plessis-Robinson, L. Modelling of controlled biofilm infection using rats with totally implantable port access intravenous catheter. In Proceedings of the European Congress of Clinical Microbiology and Infectious Diseases, Milan, Italy, 7-10 May 2011; Abstract No. O187.

36. Nett, J.E.; Marchillo, K.; Andes, D.R. Modeling of fungal biofilms using a rat central vein catheter. Methods Mol. Biol. 2012, 845, 547-556.

37. Chandra, J.; Long, L.; Ghannoum, M.A.; Mukherjee, P.K. A rabbit model for evaluation of catheter-associated fungal biofilms. Virulence 2011, 2, 466-474.

38. Ricicova, M.; Kucharikova, S.; Tournu, H.; Hendrix, J.; Bujdakova, H.; van Eldere, J.; Lagrou, K.; van Dijck, P. Candida albicans biofilm formation in a new in vivo rat model. Microbiology 2010, 156, 909-919.

39. O'Toole, G.A. Microtiter dish biofilm formation assay. J. Vis. Exp. 2011, doi:10.3791/2437.

40. Stepanovic, S.; Cirkovic, I.; Ranin, L.; Svabic-Vlahovic, M. Biofilm formation by Salmonella spp. and Listeria monocytogenes on plastic surface. Lett. Appl. Microbiol. 2004, 38, 428-432.

41. Taff, H.T.; Nett, J.E.; Andes, D.R. Comparative analysis of Candida biofilm quantitation assays. Med. Mycol. 2011, 50, 214-218.

42. Kuhn, D.M.; Balkis, M.; Chandra, J.; Mukherjee, P.K.; Ghannoum, M.A. Uses and limitations of the XTT assay in studies of Candida growth and metabolism. J. Clin. Microbiol. 2003, 41, 506-508.

43. Hawser, S.P.; Norris, H.; Jessup, C.J.; Ghannoum, M.A. Comparison of a 2,3-bis(2-methoxy-4nitro-5-sulfophenyl)-5-[(phenylamino)carbonyl]-2H-t etrazolium hydroxide (XTT) colorimetric method with the standardized National Committee for Clinical Laboratory Standards method of testing clinical yeast isolates for susceptibility to antifungal agents. J. Clin. Microbiol. 1998, 36, 1450-1452.

44. Levitz, S.M.; Diamond, R.D. A rapid colorimetric assay of fungal viability with the tetrazolium salt MTT. J. Infect. Dis. 1985, 152, 938-945. 
45. Pierce, C.G.; Uppuluri, P.; Tristan, A.R.; Wormley, F.L., Jr.; Mowat, E.; Ramage, G.; Lopez-Ribot, J.L. A simple and reproducible 96-well plate-based method for the formation of fungal biofilms and its application to antifungal susceptibility testing. Nat. Protoc. 2008, 3, 1494-1500.

46. Ramage, G.; Vande Walle, K.; Wickes, B.L.; Lopez-Ribot, J.L. Standardized method for in vitro antifungal susceptibility testing of Candida albicans biofilms. Antimicrob. Agents Chemother. 2001, 45, 2475-2479.

47. Kumar, C.P.; Menon, T. Biofilm production by clinical isolates of Candida species. Med. Mycol. 2006, 44, 99-101.

48. Guembe, M.; Guinea, J.; Marcos-Zambrano, L.; Fernandez-Cruz, A.; Pelaez, T.; Munoz, P.; Bouza, E. Is biofilm production a predictor of catheter-related candidemia? Med. Mycol. 2014, 52, 407-410.

49. Ruiz, L.S.; Khouri, S.; Hahn, R.C.; da Silva, E.G.; de Oliveira, V.K.; Gandra, R.F.; Paula, C.R. Candidemia by species of the Candida parapsilosis complex in children's hospital: Prevalence, biofilm production and antifungal susceptibility. Mycopathologia 2013, 175, 231-239.

50. Douglas, L.J. Medical importance of biofilms in Candida infections. Rev. Iberoam. Micol. 2002, 19, 139-143.

51. Kojic, E.M.; Darouiche, R.O. Candida infections of medical devices. Clin. Microbiol. Rev. 2004, 17, 255-267.

52. Ramage, G.; Martinez, J.P.; Lopez-Ribot, J.L. Candida biofilms on implanted biomaterials: A clinically significant problem. FEMS Yeast Res. 2006, 6, 979-986.

53. Swindell, K.; Lattif, A.A.; Chandra, J.; Mukherjee, P.K.; Ghannoum, M.A. Parenteral lipid emulsion induces germination of Candida albicans and increases biofilm formation on medical catheter surfaces. J. Infect. Dis. 2009, 200, 473-480.

54. Opilla, M. Epidemiology of bloodstream infection associated with parenteral nutrition. Am. J. Infect. Control 2008, 36, S173.e5-S173.e8.

55. Melo, A.S.; Bizerra, F.C.; Freymuller, E.; Arthington-Skaggs, B.A.; Colombo, A.L. Biofilm production and evaluation of antifungal susceptibility amongst clinical Candida spp. isolates, including strains of the Candida parapsilosis complex. Med. Mycol. 2011, 49, 253-262.

56. Lewis, R.E.; Kontoyiannis, D.P.; Darouiche, R.O.; Raad, I.I.; Prince, R.A. Antifungal activity of amphotericin B, fluconazole, and voriconazole in an in vitro model of Candida catheter-related bloodstream infection. Antimicrob. Agents Chemother. 2002, 46, 3499-3505.

57. Uppuluri, P.; Srinivasan, A.; Ramasubramanian, A.; Lopez-Ribot, J.L. Effects of fluconazole, amphotericin B, and caspofungin on Candida albicans biofilms under conditions of flow and on biofilm dispersion. Antimicrob. Agents Chemother. 2011, 55, 3591-3593.

58. Shuford, J.A.; Piper, K.E.; Steckelberg, J.M.; Patel, R. In vitro biofilm characterization and activity of antifungal agents alone and in combination against sessile and planktonic clinical Candida albicans isolates. Diagn. Microbiol. Infect. Dis. 2007, 57, 277-281.

59. Shi, W.; Chen, Z.; Chen, X.; Cao, L.; Liu, P.; Sun, S. The combination of minocycline and fluconazole causes synergistic growth inhibition against Candida albicans: An in vitro interaction of antifungal and antibacterial agents. FEMS Yeast Res. 2010, 10, 885-893. 
60. Kuhn, D.M.; George, T.; Chandra, J.; Mukherjee, P.K.; Ghannoum, M.A. Antifungal susceptibility of Candida biofilms: Unique efficacy of amphotericin B lipid formulations and echinocandins. Antimicrob. Agents Chemother. 2002, 46, 1773-1780.

61. Bachmann, S.P.; Ramage, G.; VandeWalle, K.; Patterson, T.F.; Wickes, B.L.; Lopez-Ribot, J.L. Antifungal combinations against Candida albicans biofilms in vitro. Antimicrob. Agents Chemother. 2003, 47, 3657-3659.

62. Tobudic, S.; Kratzer, C.; Lassnigg, A.; Graninger, W.; Presterl, E. In vitro activity of antifungal combinations against Candida albicans biofilms. J. Antimicrob. Chemother. 2010, 65, 271-274.

63. Simitsopoulou, M.; Peshkova, P.; Tasina, E.; Katragkou, A.; Kyrpitzi, D.; Velegraki, A.; Walsh, T.J.; Roilides, E. Speciespecific and drug-specific differences in susceptibility of Candida biofilms to echinocandins: Characterization of less common bloodstream isolates. Antimicrob. Agents Chemother. 2013, 57, 2562-2570.

64. Guembe, M.; Guinea, J.; Marcos-Zambrano, L.J.; Fernandez-Cruz, A.; Pelaez, T.; Munoz, P.; Bouza, E. Micafungin at physiological serum concentrations shows antifungal activity against Candida albicans and Candida parapsilosis biofilms. Antimicrob. Agents Chemother. 2014, 58, 5581-5584.

65. Choi, H.W.; Shin, J.H.; Jung, S.I.; Park, K.H.; Cho, D.; Kee, S.J.; Shin, M.G.; Suh, S.P.; Ryang, D.W. Species-specific differences in the susceptibilities of biofilms formed by Candida bloodstream isolates to echinocandin antifungals. Antimicrob. Agents Chemother. 2007, 51, 1520-1523.

66. Bachmann, S.P.; VandeWalle, K.; Ramage, G.; Patterson, T.F.; Wickes, B.L.; Graybill, J.R.; López-Ribot, J.L. In vitro activity of caspofungin against Candida albicans biofilms. Antimicrob. Agents Chemother. 2002, 46, 3591-3596.

67. Rosato, A.; Piarulli, M.; Schiavone, B.P.; Catalano, A.; Carocci, A.; Carrieri, A.; Carone, A.; Caggiano, G.; Franchini, C.; Corbo, F.; et al. In vitro effectiveness of anidulafungin against Candida sp. biofilms. J. Antibiot. (Tokyo) 2013, 66, 701-704.

68. Jacobson, M.J.; Piper, K.E.; Nguyen, G.; Steckelberg, J.M.; Patel, R. In vitro activity of anidulafungin against Candida albicans biofilms. Antimicrob. Agents Chemother. 2008, 52, 2242-2243.

69. Valentin, A.; Canton, E.; Peman, J.; Quindos, G. In vitro activity of amphotericin B and anidulafungin against Candida spp. biofilms. Rev. Iberoam. Micol. 2007, 24, 272-277.

70. Fiori, B.; Posteraro, B.; Torelli, R.; Tumbarello, M.; Perlin, D.S.; Fadda, G.; Sanguinetti, M. In vitro activities of anidulafungin and other antifungal agents against biofilms formed by clinical isolates of different Candida and Aspergillus species. Antimicrob. Agents Chemother. 2011, 55, 3031-3035.

71. Nweze, E.I.; Ghannoum, A.; Chandra, J.; Ghannoum, M.A.; Mukherjee, P.K. Development of a 96-well catheter-based microdilution method to test antifungal susceptibility of Candida biofilms. J. Antimicrob. Chemother. 2012, 67, 149-153.

72. Bernhardt, H.; Knoke, M.; Bernhardt, J. Efficacy of anidulafungin against biofilms of different Candida species in long-term trials of continuous flow cultivation. Mycoses 2011, 54, e821-e827.

73. Jacobson, M.J.; Steckelberg, K.E.; Piper, K.E.; Steckelberg, J.M.; Patel, R. In vitro activity of micafungin against planktonic and sessile Candida albicans isolates. Antimicrob. Agents Chemother. 2009, 53, 2638-2639. 
74. Miceli, M.H.; Bernardo, S.M.; Lee, S.A. In vitro analysis of the occurrence of a paradoxical effect with different echinocandins and Candida albicans biofilms. Int. J. Antimicrob. Agents. 2009, 34, 500-502.

75. $\mathrm{Ku}, \mathrm{T} . \mathrm{S}$.; Bernardo, S.M.; Lee, S.A. In vitro assessment of the antifungal and paradoxical activity of different echinocandins against Candida tropicalis biofilms. J. Med. Microbiol. 2011, 60, 1708-1170.

76. Ferreira, J.A.; Carr, J.H.; Starling, C.E.; de Resende, M.A.; Donlan, R.M. Biofilm formation and effect of caspofungin on biofilm structure of Candida species bloodstream isolates. Antimicrob. Agents Chemother. 2009, 53, 4377-4384.

77. Peman, J.; Canton, E.; Valentin, A. Activity of anidulafungin against Candida biofilms. Rev. Iberoam Micol. 2008, 25, 124-128.

78. Cocuaud, C.; Rodier, M.H.; Daniault, G.; Imbert, C. Anti-metabolic activity of caspofungin against Candida albicans and Candida parapsilosis biofilms. J. Antimicrob. Chemother. 2005, 56, 507-512.

79. Kaneko, Y.; Miyagawa, S.; Takeda, O.; Hakariya, M.; Matsumoto, S.; Ohno, H.; Miyazaki, Y. Real-time microscopic observation of Candida biofilm development and effects due to micafungin and fluconazole. Antimicrob. Agents Chemother. 2013, 57, 2226-2230.

80. Seidler, M.; Salvenmoser, S.; Muller, F.M. In vitro effects of micafungin against Candida biofilms on polystyrene and central venous catheter sections. Int. J. Antimicrob. Agents 2006, 28, 568-573.

81. Toulet, D.; Debarre, C.; Imbert, C. Could liposomal amphotericin B (L-AMB) lock solutions be useful to inhibit Candida spp. biofilms on silicone biomaterials? J. Antimicrob. Chemother. 2011, 67, 430-432.

82. Oncu, S. In vitro effectiveness of antifungal lock solutions on catheters infected with Candida species. J. Infect. Chemother. 2011, 17, 634-639.

83. Cateau, E.; Rodier, M.H.; Imbert, C. In vitro efficacies of caspofungin or micafungin catheter lock solutions on Candida albicans biofilm growth. J. Antimicrob. Chemother. 2008, 62, 153-155.

84. Cateau, E.; Berjeaud, J.M.; Imbert, C. Possible role of azole and echinocandin lock solutions in the control of Candida biofilms associated with silicone. Int. J. Antimicrob. Agents. 2011, 37, 380-384.

85. Ko, K.S.; Lee, J.Y.; Song, J.H.; Peck, K.R. In vitro evaluation of antibiotic lock technique for the treatment of Candida albicans, C. glabrata, and C. tropicalis biofilms. J. Korean Med. Sci. 2010, 25, 1722-1726.

86. Pires, R.H.; Montanari, L.B.; Martins, C.H.; Zaia, J.E.; Almeida, A.M.; Matsumoto, M.T.; Mendes-Gianinni, M.J.S. Anticandidal efficacy of cinnamon oil against planktonic and biofilm cultures of Candida parapsilosis and Candida orthopsilosis. Mycopathologia 2011, 172, 453-464.

87. Rukayadi, Y.; Han, S.; Yong, D.; Hwang, J.K. In vitro activity of xanthorrhizol against Candida glabrata, C. guilliermondii, and C. parapsilosis biofilms. Med. Mycol. 2011, 49, 1-9.

88. Percival, S.L.; Kite, P.; Eastwood, K.; Murga, R.; Carr, J.; Arduino, M.J.; Donlan, R.M. Tetrasodium EDTA as a novel central venous catheter lock solution against biofilm. Infect. Control Hosp. Epidemiol. 2005, 26, 515-519.

89. Rane, H.S.; Bernardo, S.M.; Walraven, C.J.; Lee, S.A. In vitro analyses of ethanol activity against Candida albicans biofilms. Antimicrob. Agents Chemother. 2013, 56, 4487-4479. 
90. Raad, I.; Rosenblatt, J.; Reitzel, R.; Jiang, Y.; Dvorak, T.; Hachem, R. Chelator-based catheter lock solutions in eradicating organisms in biofilm. Antimicrob. Agents Chemother. 2013, 57, 586-588.

91. Raad, I.; Hanna, H.; Dvorak, T.; Chaiban, G.; Hachem, R. Optimal antimicrobial catheter lock solution, using different combinations of minocycline, EDTA, and 25-percent ethanol, rapidly eradicates organisms embedded in biofilm. Antimicrob. Agents Chemother. 2007, 51, 78-83.

92. Rosenblatt, J.; Reitzel, R.; Dvorak, T.; Jiang, Y.; Hachem, R.Y.; Raad, I.I. Glyceryl trinitrate complements citrate and ethanol in a novel antimicrobial catheter lock solution to eradicate biofilm organisms. Antimicrob. Agents Chemother. 2013, 57, 3555-3560.

93. Mukherjee, P.K.; Long, L.; Kim, H.G.; Ghannoum, M.A. Amphotericin B lipid complex is efficacious in the treatment of Candida albicans biofilms using a model of catheter-associated Candida biofilms. Int. J. Antimicrob. Agents 2009, 33, 149-153.

94. Schinabeck, M.K.; Long, L.A.; Hossain, M.A.; Chandra, J.; Mukherjee, P.K.; Mohamed, S.; Ghannoum, M.A. Rabbit model of Candida albicans biofilm infection: Liposomal amphotericin B antifungal lock therapy. Antimicrob. Agents Chemother. 2004, 48, 1727-1732.

95. Shuford, J.A.; Rouse, M.S.; Piper, K.E.; Steckelberg, J.M.; Patel, R. Evaluation of caspofungin and amphotericin B deoxycholate against Candida albicans biofilms in an experimental intravascular catheter infection model. J. Infect. Dis. 2006, 194, 710-713.

96. Lazzell, A.L.; Chaturvedi, A.K.; Pierce, C.G.; Prasad, D.; Uppuluri, P.; Lopez-Ribot, J.L. Treatment and prevention of Candida albicans biofilms with caspofungin in a novel central venous catheter murine model of candidiasis. J. Antimicrob. Chemother. 2009, 64, 567-570.

97. Kucharikova, S.; Sharma, N.; Spriet, I.; Maertens, J.; van Dijck, P.; Lagrou, K. Activities of systemically administered echinocandins against in vivo mature Candida albicans biofilms developed in a rat subcutaneous model. Antimicrob. Agents Chemother. 2013, 57, 2365-2368.

98. Kucharikova, S.; Tournu, H.; Holtappels, M.; van Dijck, P.; Lagrou, K. In vivo efficacy of anidulafungin against mature Candida albicans biofilms in a novel rat model of catheter-associated Candidiasis. Antimicrob. Agents Chemother. 2010, 4, 4474-4475.

99. Pappas, P.G.; Kauffman, C.A.; Andes, D.; Benjamin, D.K., Jr., Calandra, T.F.; Edwards, J.E., Jr.; Filler, S.G.; Fisher, J.F.; Kullberg, B.J.; Ostrosky-Zeichner, L.; et al. Clinical practice guidelines for the management of candidiasis: 2009 update by the Infectious Diseases Society of America. Clin. Infect. Dis. 2009, 48, 503-535.

100. Samore, M.H.; Burke, J.P. Infections of long intravenous lines: New developments and controversies. Curr. Clin. Top. Infect. Dis. 2000, 20, 256-270.

101. Nucci, M.; Anaissie, E.; Betts, R.F.; Dupont, B.F.; Wu, C.; Buell, D.N.; Kovanda, L.; Lortholary, O. Early removal of central venous catheter in patients with candidemia does not improve outcome: Analysis of 842 patients from 2 randomized clinical trials. Clin. Infect. Dis. 2010, 51, 295-303.

102. Brass, E.P.; Edwards, J.E. Should the guidelines for management of central venous catheters in patients with candidemia be changed now? Clin. Infect. Dis. 2010, 51, 304-306.

103. Koh, G.C.; Luong, M.L. Early removal of central venous catheters and outcomes from candidemia. Clin. Infect. Dis. 2010, 51, 1347. 
104. Garnacho-Montero, J.; Diaz-Martin, A.; Garcia-Cabrera, E.; Ruiz Perez de Pipaon, M.; Hernandez-Caballero, C.; Lepe-Jimenez, J.A. Impact on hospital mortality of catheter removal and adequate antifungal therapy in Candida spp. bloodstream infections. J. Antimicrob. Chemother. 2013, 68, 206-213.

105. Tumbarello, M.; Fiori, B.; Trecarichi, E.M.; Posteraro, P.; Losito, A.R.; de Luca, A.; Sanguinetti, M.; Fadda, G.; Cauda, R.; Posteraro, B. Risk factors and outcomes of candidemia caused by biofilm-forming isolates in a tertiary care hospital. PLOS ONE 2013, 7, e33705.

106. Rodriguez, D.; Park, B.J.; Almirante, B.; Cuenca-Estrella, M.; Planes, A.M.; Mensa, J.; Gimenez, M.; Saballs, P.; Fridkin, S.K.; Rodriguez-Tudela, J.L.; et al. Impact of early central venous catheter removal on outcome in patients with candidaemia. Clin. Microbiol. Infect. 2007, 13, 788-793.

107. Raad, I.I.; Fang, X.; Keutgen, X.M.; Jiang, Y.; Sherertz, R.; Hachem, R. The role of chelators in preventing biofilm formation and catheter-related bloodstream infections. Curr. Opin. Infect. Dis. 2008, 21, 385-392.

108. Walraven, C.J.; Lee, S.A. Antifungal lock therapy. Antimicrob. Agents Chemother. 2013, 57, 1-8.

109. Cobrado, L.; Silva-Dias, A.; Azevedo, M.M.; Pina-Vaz, C.; Rodrigues, A.G. In vivo antibiofilm effect of cerium, chitosan and hamamelitannin against usual agents of catheter-related bloodstream infections. J. Antimicrob. Chemother. 2013, 68, 126-130.

110. Raad, I.; Mohamed, J.A.; Reitzel, R.A.; Jiang, Y.; Raad, S.; al Shuaibi, M.; Chaftari, A.M.; Hachem, R.Y. Improved antibiotic-impregnated catheters with extended-spectrum activity against resistant bacteria and fungi. Antimicrob. Agents Chemother. 2011, 56, 935-941.

111. Maki, D.G. In vitro studies of a novel antimicrobial luer-activated needleless connector for prevention of catheter-related bloodstream infection. Clin. Infect. Dis. 2010, 50, 1580-1587.

112. Khare, M.D.; Bukhari, S.S.; Swann, A.; Spiers, P.; McLaren, I.; Myers, J. Reduction of catheter-related colonisation by the use of a silver zeolite-impregnated central vascular catheter in adult critical care. J. Infect. 2007, 54, 146-150.

113. Martinez, L.R.; Mihu, M.R.; Tar, M.; Cordero, R.J.; Han, G.; Friedman, A.J.; Friedman, J.M.; Nosanchuk, J.D. Demonstration of antibiofilm and antifungal efficacy of chitosan against candidal biofilms, using an in vivo central venous catheter model. J. Infect. Dis. 2012, 201, 1436-1440.

114. Mermel, L.A.; Allon, M.; Bouza, E.; Craven, D.E.; Flynn, P.; O’Grady, N.P.; Raad, I.I.; Rijnders, B.J.; Sherertz, R.J.; Warren, D.K. Clinical practice guidelines for the diagnosis and management of intravascular catheter-related infection: 2009 Update by the Infectious Diseases Society of America. Clin. Infect. Dis. 2009, 49, 1-45.

115. Pieroni, K.P.; Nespor, C.; Poole, R.L.; Kerner, J.A., Jr.; Berquist, W.E. Echinocandin and ethanol lock therapy treatment of fungal catheter infections. Pediatr. Infect. Dis. J. 2013, 32, 289-291.

116. Carratala, J. The antibiotic-lock technique for therapy of "highly needed" infected catheters. Clin. Microbiol. Infect. 2002, 8, 282-289.

117. Messing, B.; Peitra-Cohen, S.; Debure, A, Beliah, M.; Bernier, J.J. Antibiotic-lock technique: A new approach to optimal therapy for catheter-related sepsis in home-parenteral nutrition patients. JPEN J. Parenter Enteral Nutr. 1988, 12, 185-189.

118. Benoit, J.L.; Carandang, G.; Sitrin, M.; Arnow, P. Intraluminal antibiotic treatment of central venous catheter infections in patients receiving parenteral nutrition at home. Clin. Infect. Dis. 1997, $24,743-744$. 
119. Krzywda, E.A.; Andris, D.A.; Edmiston, C.E., Jr.; Quebbeman, E.J. Treatment of Hickman catheter sepsis using antibiotic lock technique. Infect. Control Hosp. Epidemiol. 1995, 16, 596-598.

120. Ozdemir, H.; Karbuz, A.; Ciftci, E.; Dincaslan, H.U.; Ince, E.; Aysev, D.; Yavuz, G.; Doğru, U. Successful treatment of central venous catheter infection due to Candida lipolytica by caspofungin-lock therapy. Mycoses 2011, 54, e647-e649.

121. Arnow, P.M.; Kushner, R. Malassezia furfur catheter infection cured with antibiotic lock therapy. Am. J. Med. 1991, 90, 128-130.

122. Johnson, D.C.; Johnson, F.L.; Goldman, S. Preliminary results treating persistent central venous catheter infections with the antibiotic lock technique in pediatric patients. Pediatr. Infect. Dis. J. 1994, 13, 930-931.

123. Viale, P.; Petrosillo, N.; Signorini, L.; Puoti, M.; Carosi, G. Should lock therapy always be avoided for central venous catheter-associated fungal bloodstream infections? Clin. Infect. Dis. 2001, 33, 1947-1978.

124. Castagnola, E.; Marazzi, M.G.; Tacchella, A.; Giacchino, R. Broviac catheter-related candidemia. Pediatr. Infect. Dis. J. 2005, 24, 747.

125. Angel-Moreno, A.; Boronat, M.; Bolanos, M.; Carrillo, A.; Gonzalez, S.; Perez Arellano, J.L. Candida glabrata fungemia cured by antibiotic-lock therapy: Case report and short review. J. Infect. 2005, 51, e85-e87.

126. Wu, C.Y.; Lee, P.I. Antibiotic-lock therapy and erythromycin for treatment of catheter-related Candida parapsilosis and Staphylococcus aureus infections. J. Antimicrob. Chemother. 2007, 60, 706-707.

127. Buckler, B.S.; Sams, R.N.; Goei, V.L.; Krishnan, K.R.; Bemis, M.J.; Parker, D.P.; Murray, D.L. Treatment of central venous catheter fungal infection using liposomal amphotericin-B lock therapy. Pediatr. Infect. Dis. J. 2008, 27, 762-764.

128. Blackwood, R.A.; Klein, K.C.; Micel, L.N.; Willers, M.L.; Mody, R.J.; Teitelbaum, D.H.; Cober, M.P. Ethanol locks therapy for resolution of fungal catheter infections. Pediatr. Infect. Dis. J. 2011, 30, 1105-1107.

129. Shorr, A.F.; Wu, C.; Kothari, S. Outcomes with micafungin in patients with candidaemia or invasive candidiasis due to Candida glabrata and Candida krusei. J. Antimicrob. Chemother. 2011, 66, $375-380$.

130. Aikawa, N.; Kusachi, S.; Oda, S.; Takesue, Y.; Tanaka, H. Clinical effects of micafungin, a novel echinocandin antifungal agent, on systemic fungal infections in surgery, emergency, and intensive-care medicine: Evaluation using the AKOTT algorithm. J. Infect. Chemother. 2009, 15, 219-227.

131. Cornely, O.A.; Pappas, P.G.; Young, J.A.; Maddison, P.; Ullmann, A.J. Accumulated safety data of micafungin in therapy and prophylaxis in fungal diseases. Expert Opin. Drug Saf. 2011, 10, 171-183.

132. Manzoni, P.; Benjamin, D.K.; Hope, W.; Rizzollo, S.; Del Sordo, P.; Stronati, M.; Jacqz-Aigrain, E.; Castagnola, E.; Farina, D. The management of Candida infections in preterm neonates and the role of micafungin. J. Matern. Fetal Neonatal. Med. 2011, 24, 24-27. 
133. Queiroz-Telles, F.; Berezin, E.; Leverger, G.; Freire, A.; van der Vyver, A.; Chotpitayasunondh, T.; Konja, J.; Diekmann-Berndt, H.; Koblinger, S.; Groll, A.H.; et al. Micafungin versus liposomal amphotericin B for pediatric patients with invasive candidiasis: Substudy of a randomized double-blind trial. Pediatr. Infect. Dis. J. 2008, 27, 820-826.

134. Privett, B.J.; Nutz, S.T.; Schoenfisch, M.H. Efficacy of surface-generated nitric oxide against Candida albicans adhesion and biofilm formation. Biofouling 2010, 26, 973-983.

135. Roe, D.; Karandikar, B.; Bonn-Savage, N.; Gibbins, B.; Roullet, J.B. Antimicrobial surface functionalization of plastic catheters by silver nanoparticles. J. Antimicrob. Chemother. 2008, 61, 869-876.

136. Hanna, H.; Bahna, P.; Reitzel, R.; Dvorak, T.; Chaiban, G.; Hachem, R.; Raad, I. Comparative in vitro efficacies and antimicrobial durabilities of novel antimicrobial central venous catheters. Antimicrob. Agents Chemother. 2006, 50, 3283-3288.

137. Carrasco, M.N.; Bueno, A.; de las Cuevas, C.; Jimenez, S.; Salinas, I.; Sartorius, A.; Recio, T.; Generelo, M.; Ruiz-Ocaña, F. Evaluation of a triple-lumen central venous heparin-coated catheter vs. a catheter coated with chlorhexidine and silver sulfadiazine in critically ill patients. Intensive Care Med. 2004, 30, 633-638.

138. Walz, J.M.; Avelar, R.L.; Longtine, K.J.; Carter, K.L.; Mermel, L.A.; Heard, S.O. Anti-infective external coating of central venous catheters: A randomized, noninferiority trial comparing 5-fluorouracil with chlorhexidine/silver sulfadiazine in preventing catheter colonization. Crit. Care Med. 2010, 38, 2095-2102.

139. Menyhay, S.Z; Maki, D.G. Disinfection of needleless catheter connectors and access ports with alcohol may not prevent microbial entry: The promise of a novel antiseptic-barrier cap. Infect. Control Hosp. Epidemiol. 2006, 27, 23-27.

140. Menyhay, S.Z.; Maki, D.G. Preventing central venous catheter-associated bloodstream infections: Development of an antiseptic barrier cap for needleless connectors. Am. J. Infect. Control. 2008, 36, S174.e1-S174.e5.

141. Leon, C.; Alvarez-Lerma, F.; Ruiz-Santana, S.; Gonzalez, V.; de la Torre, M.V.; Sierra, R.; León, M.; Rodrigo, J.J. Antiseptic chamber-containing hub reduces central venous catheter-related infection: A prospective, randomized study. Crit. Care Med. 2003, 31, 1318-1324.

(C) 2014 by the authors; licensee MDPI, Basel, Switzerland. This article is an open access article distributed under the terms and conditions of the Creative Commons Attribution license (http://creativecommons.org/licenses/by/4.0/). 